\title{
Sex Differences in BNST and Amygdala Activation by Contextual, Cued, and Unpredictable Threats
}

\author{
Louise Urien and Elizabeth P. Bauer
}

https://doi.org/10.1523/ENEURO.0233-21.2021

Departments of Biology and Neuroscience and Behavior, Barnard College of Columbia University, New York, NY 10027

\begin{abstract}
Fear and anxiety can be described as emotional and physical responses to predictable and unpredictable threats. While the amygdala is necessary for context and cued fear conditioning, the bed nucleus of the stria terminalis (BNST) is important for anxiety-like behavior and conditioned responses to diffuse and/or unpredictable threats. However, we still lack knowledge about how the BNST and amygdala nuclei act in coordination. Moreover, the incidence of anxiety disorders and posttraumatic stress disorder (PTSD) is substantially higher in women than in men, but most studies of fear conditioning are conducted in male rodents. Here, we asked whether the BNST and the lateral, basal, and central nuclei of the amygdala are active during the expression of fear conditioning in male and female rats using FOS immunohistochemistry. We first show that the BNST is indeed involved in context fear expression in males, but not in females. The lateral amygdala was active in both sexes during context fear expression. We next trained animals using tone cues paired with an unconditioned stimulus (US), or tone cues which were unpaired with the US, and thus nonpredictive. Females displayed greater fear expression to these unpaired tones than males. FOS was upregulated in both the BNST and the basal amygdala during fear expression to unpaired tones in both sexes. The differential processing of fear responses by males and females highlights the need to acknowledge sex differences in conditioned fear memory.
\end{abstract}

Key words: amygdala; conditioning; fear; FOS; threat

\section{Significance Statement}

The prevalence of anxiety disorders and posttraumatic stress disorder (PTSD) is substantially higher in women than in men. Abnormalities in conditioned fear characterize many of these disorders. Sex differences have been reported for some forms of fear conditioning, but the neural circuits underlying these differences are not fully understood. Here, we quantified neural activity in three regions of the amygdala as well as the bed nucleus of the stria terminalis (BNST) in response to fear expression to context and cued fear conditioning. Our results indicate different patterns of activity in the BNST and amygdala in males and females during context fear expression. Second, while females showed enhanced behavioral responding to unpaired tones, the BNST and basal nucleus of the amygdala were similarly activated in males and females.

\section{Introduction}

Atypical fear learning, expression, and extinction characterize many stress-related psychopathologies (Gorman et al., 2000; Milad et al., 2006; Maren and Holmes, 2016). Incorrectly attributing danger to a safety cue is a hallmark

Received May 21, 2021; accepted November 22, 2021; First published December 15, 2021.

The authors declare no competing financial interests. of anxiety disorders and posttraumatic stress disorder (PTSD). Moreover, fear responses are often linked to a specific context in which the environment itself is threatening. For example, patients suffering from PTSD exhibit "re-experiencing" when they are reminded of a traumatic event by being exposed to the same environment

Author contributions: L.U. and E.P.B. designed research; L.U. performed research; L.U. and E.P.B. analyzed data; L.U. and E.P.B. wrote the paper. 
previously associated with the trauma. Recent studies in both men and women reveal that these disorders are associated with changes in neural activity in both the amygdala and the bed nucleus of the stria terminalis (BNST; Sripada et al., 2012; Avery et al., 2016; Brinkmann et al., 2017a,b; Rabellino et al., 2018; Shackman and Fox, 2021). However, the prevalence of anxiety disorders and PTSD is substantially higher in women than in men (Altemus et al., 2014; Kimerling et al., 2018).

While decades of research have focused on the role of the amygdala in Pavlovian fear conditioning (Fanselow and LeDoux, 1999; Pape and Pare, 2010), the BNST is emerging as a crucial contributor to conditioned fear. Early research in rodents using lesions and temporary inactivation established that the BNST is necessary for the expression but not the acquisition of context fear conditioning (Walker et al., 2003; Sullivan et al., 2004; Duvarci, et al., 2009). This led to the idea that the BNST is crucial for conditioning to sustained cues (including context) but not discrete cues (Davis et al., 2010). More recent work in both rodents and humans suggests that the BNST also contributes to conditioning to unpredictable cues (Figel et al., 2019; Goode et al., 2019; Naaz et al., 2019).

The BNST of males and females have clear volumetric and neurochemical differences (del Abril et al., 1987; Allen and Gorski, 1990; Hines et al., 1992) and areas of the BNST involved in reproductive function show different patterns of connectivity in males and females (Polston et al., 2004). Many of these differences are acquired during the early stages of development and are attributable to different hormonal influences (Stefanova and Ovtscharoff, 2007). Sexual dimorphism in the BNST could in part explain some differences observed in contextual fear conditioning, where female rodents exhibit less freezing behaviors than males (Archer, 1975; Maren, et al., 1994; Fanselow and Dong, 2010; Colon et al., 2018; Colon and Poulos, 2020). However, others find stronger conditioning in females (Moore et al., 2010; Keiser et al., 2017), while still others find no differences in context fear expression (Dachtler et al., 2011; Urien et al., 2021).

The BNST is often referred to as the extended amygdala (Alheid and Heimer, 1988; Swanson and Petrovich, 1998; Fox et al., 2015). It receives glutamatergic input from the basolateral nucleus of the amygdala (Krettek and Price, 1978; Smith and Paré, 1994; Paré et al., 1995), and it is reciprocally connected with the central nucleus (CE) of the amygdala (Sun and Cassell, 1993; Shin et al., 2008). All of these amygdala nuclei play a key role in the acquisition of Pavlovian cued fear conditioning (Repa et al., 2001; Herry et al., 2008; Ciocchi et al., 2010). While some studies have found reduced cued fear conditioning

This work was supported by the National Institutes of Health Grant 1R15MH107008 (to E.P.B.).

Correspondence should be addressed to Elizabeth P. Bauer at ebauer@ barnard.edu.

https://doi.org/10.1523/ENEURO.0233-21.2021

Copyright (C) 2022 Urien and Bauer

This is an open-access article distributed under the terms of the Creative Commons Attribution 4.0 International license, which permits unrestricted use, distribution and reproduction in any medium provided that the original work is properly attributed. in females (Pryce et al., 1999; Baran et al., 2010), most find no sex differences (Baker-Andresen et al., 2013; Fenton et al., 2014; Voulo and Parsons, 2017; Day et al., 2020). Interestingly, female rodents show more generalization of fear to novel and safe contexts and cues (Day et al., 2016; Keiser et al., 2017). They also show deficits in conditioned inhibition compared with males (Krueger and Sangha, 2021). In human studies, females discriminate less between fear and safety signals (Lonsdorf and Kalisch, 2011; Gamwell et al., 2015).

This study directly compared neural activation, as indexed by FOS immunohistochemistry, in four interconnected regions: the BNST, the $L A$, the $C E$, and the BA in both male and female rats after conditioned fear expression. Animals underwent context fear conditioning, or either paired or unpaired cued fear conditioning. By directly comparing behavior and patterns of neuronal activation, we aimed to reveal both similarities and differences in fear expression in males and females.

\section{Materials and Methods}

\section{Subjects}

Male $(n=36 ; 250-325 \mathrm{~g})$ and female $(n=44 ; 225-275 \mathrm{~g})$ Sprague Dawley rats were purchased from Charles River Laboratories. They were housed in pairs, with ad libitum access to food and water, and maintained on a 12/12 $\mathrm{h}$ light/dark cycle. All behavioral experiments were performed during the light cycle between 8 and 11 A.M. All procedures were approved by Columbia University's Animal Care and Use Committee in accordance with the National Institutes of Health Guide for the Care and Use of Laboratory Animals.

\section{Context fear conditioning}

On day 1 , rats were habituated to the context for $10 \mathrm{~min}$ which consisted of a standard conditioning chamber with a metal grid floor (Coulbourn Instruments). On day 2, animals were placed in the conditioning chamber for $10 \mathrm{~min}$ and received three unsignaled footshocks $(0.5 \mathrm{~mA}, 1 \mathrm{~s})$. Animals in the "no shock" group were placed in conditioning chambers for $10 \mathrm{~min}$ on day 2 but did not receive shocks. On day 3 , animals were returned to the conditioning chamber for $10 \mathrm{~min}$. Total time spent freezing after the shock during conditioning ( $30 \mathrm{~s}$ ) and to the context during testing (freezing time per minute over $10 \mathrm{~min}$ ) was manually scored offline for each animal by an observer blind to group assignment.

\section{Cued fear conditioning}

On day 1 , rats were habituated to the context $A$ for 10 min, which consisted of a standard conditioning chamber with a metal grid floor (Coulbourn Instruments). On day 2 , animals were placed in the conditioning chamber in context $A$ for $10 \mathrm{~min}$ and received three signaled footshocks $(0.5 \mathrm{~mA}, 1 \mathrm{~s})$ preceded by a tone stimulus $(80 \mathrm{~dB}$, $30 \mathrm{~s})$. Animals in the no shock group were placed in the conditioning chamber in context $A$ for $10 \mathrm{~min}$, heard the tone but did not receive shocks. On day 3 , animals were placed in context $B$ and received five tones $(80 \mathrm{~dB}, 30 \mathrm{~s})$. 
Context B contained a black Plexiglas floor washed with peppermint soap, different wall materials (clear plastic or metal) and different light placement. Total time spent freezing to the tone was manually scored offline for each animal by an observer blind to group assignment.

\section{Unpaired cued fear conditioning}

On day 1 , rats were habituated to context $A$ for $10 \mathrm{~min}$ as described above. On day 2, animals were placed in the conditioning chamber in context $\mathrm{A}$ for $10 \mathrm{~min}$ and received three footshocks [0.5 mA, $1 \mathrm{~s}$, unconditioned stimulus (US) 1: 329 s; US2: 417 s; US3: $486 \mathrm{~s}$ ] and three 30 -s tone stimuli [80 dB, 30 s; conditioned stimulus (CS)1: 250 s; CS2: 430 s; CS3: $520 \mathrm{~s}$ ]. The tone CSs were explicitly unpaired with footshocks. On day 3 , animals were placed in context $B$ as described above and received five tones $(80 \mathrm{~dB}, 30 \mathrm{~s})$. Total time spent freezing to the tone was manually scored offline for each animal by an observer blind to group assignment.

\section{Immunohistochemistry}

A total of $60-90$ min after the completion of behavioral testing, animals were given an overdose of sodium pentobarbital $(100 \mathrm{mg} / \mathrm{kg})$ and perfused transcardially with $0.1 \mathrm{M}$ PBS and 4\% paraformaldehyde in $0.1 \mathrm{~m}$ PB. After perfusions, brains were postfixed for $24 \mathrm{~h}$ and transferred to a $20 \%$ sucrose solution for at least $48 \mathrm{~h}$. Tissue was sectioned at $80 \mu \mathrm{m}$ using a Vibratome. A total of 10-12 slices per animal was collected, covering the rostro-caudal extent of the BNST, and 20-24 slices were collected covering the rostro-caudal extent of the BLA and CE. Every other slice was processed and analyzed, so there was no need to correct for double counting. Tissue was washed first in $0.1 \mathrm{M}$ PB three times, then in PB with $1 \%$ Triton $X-100$ (PBT) three times for 5 min each wash. Slices were blocked in $2 \%$ normal goat serum (Vector Laboratories) in PBT for $1 \mathrm{~h}$. Slices were then incubated for $48 \mathrm{~h}$ at $4^{\circ} \mathrm{C}$ in primary polyclonal rabbit anti-cFOS antibody (1:1000, Abcam ab190289) in block solution. Slices were washed in PBT and incubated with secondary biotinylated goat anti-rabbit antibody (1:200; Vector Labs BA1000) for $1 \mathrm{~h}$ at room temperature. Slices were processed with avidin-biotin horseradish peroxidase complex (Vectastain Elite ABC kit, Vector Labs PK6100). Horseradish peroxidase was visualized with 3,3'diaminobenzidine (Sigma-Aldrich D5905) in a $3 \mathrm{~m}$ sodium acetate buffer containing $0.05 \% \mathrm{H}_{2} \mathrm{O}_{2}$. and enhanced with nickel. Slices were washed in PBS, mounted on slides and coverslipped.

\section{Microscopy}

For each brain analysis, we selected $80 \mu \mathrm{m}$ slices covering the anterior-posterior axes of each structure (BNST: $\mathrm{AP}+0.12$ to $\mathrm{AP}-0.36$; $\mathrm{CE}: \mathrm{AP}-2.50$ to $\mathrm{AP}-3.0$; BLA: $A P-2.75$ to AP -3.25 ). Delineation of the borders of each structure, and measurement of the area of each structure were made using NIS element software and ImageJ. We analyzed FOS expression in the dorsal anterolateral and anteromedial portions of the BNST as these areas are
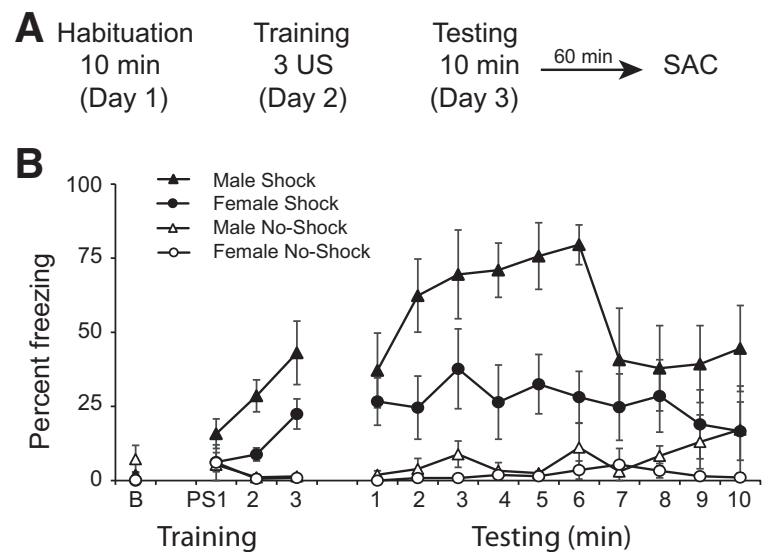

Figure 1. Context fear expression in males and females. $\boldsymbol{A}$, Schematic of behavioral protocol. B, Percent freezing +/- s.e.m. during training at baseline (B) and after three unsignaled footshocks (PS1, PS2, PS3) or the equivalent time points in animals receiving no shocks. Percent freezing during the $10 \mathrm{~min}$ of testing in males and females.

involved in context fear expression (Haufler et al., 2013). Three regions of the amygdala were analyzed: the CE, LA, and BA. Within the CE, we analyzed both the lateral (CeL) and medial (CeM) divisions. FOS-positive cells were counted manually using ImageJ software. For each animal, we analyzed left and right hemispheres separately to reveal potential lateralization of FOS activity. Two to three samples per hemisphere were averaged together and divided by the surface area of the structure to normalize cell counts by area. Thus, for each animal we obtained two measurements of FOS activity per brain structure: one measurement for the left hemisphere and one for the right hemisphere.

\section{Statistical analyses}

All statistical analyses were performed using SPSS software. Two-way repeated-measures ANOVAs assessed the effect of sex and behavioral group on freezing behavior. When appropriate, we conducted one-way ANOVAs and Tukey's HSD post hoc tests. To analyze FOS expression, mixed model ANOVAs were conducted with sex and behavioral group as between-subject factors, and laterality as a nested factor. When appropriate, we conducted one-way ANOVAs and Tukey's HSD post hoc tests. We tested for correlations between FOS expression and freezing behavior using Spearman's rank order correlation, as freezing behavior was not normally distributed. For all experiments, differences were considered significant when $p<0.05$.

\section{Results}

\section{Context fear conditioning}

Our first experiment measured upregulation of the immediate early gene FOS in the BNST and amygdala of males and females after context fear expression (Fig. 1). Animals that underwent behavioral testing were habituated to the training context for $10 \mathrm{~min}$ on day 1 . During 

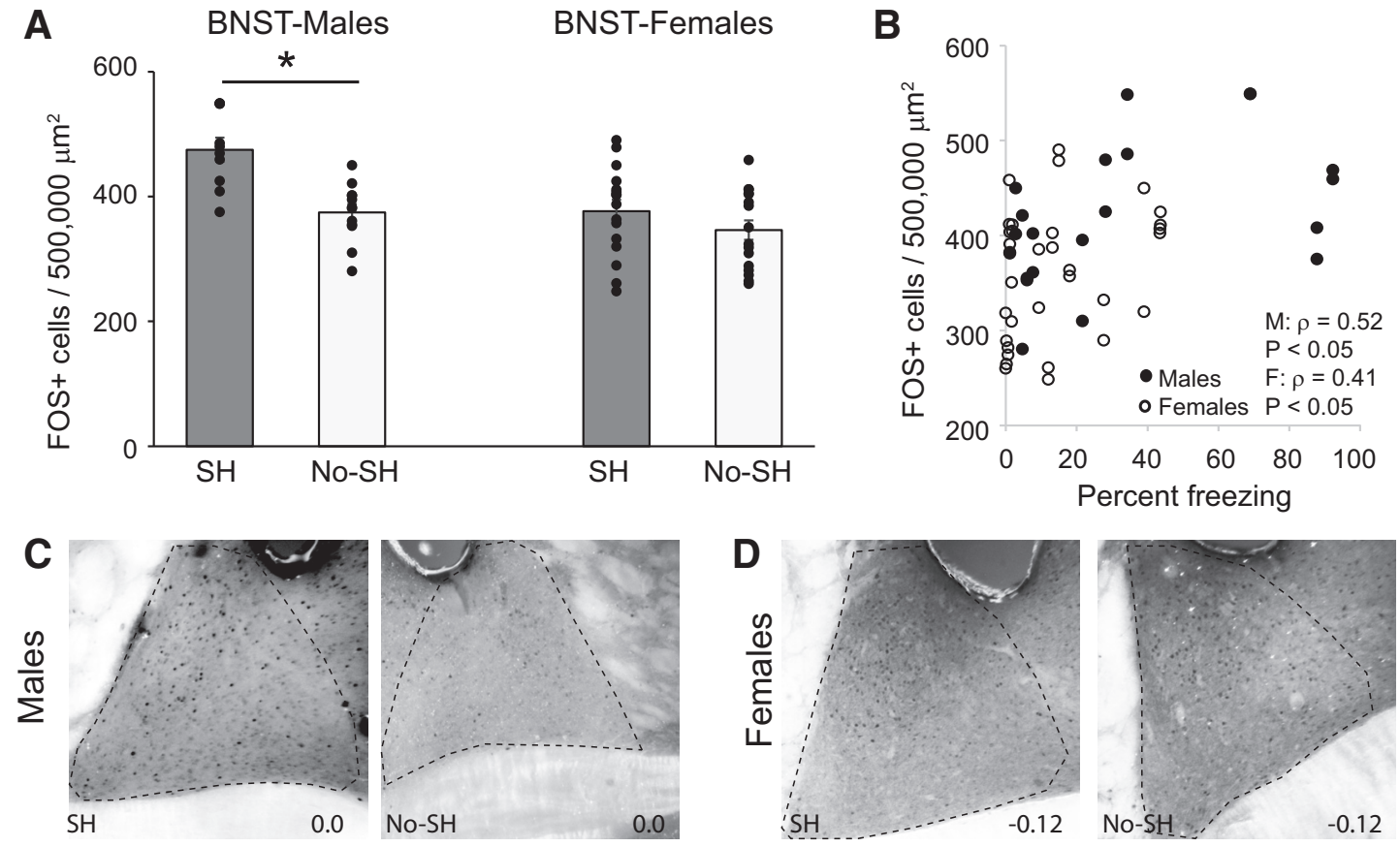

Figure 2. Differential effects of context fear expression on FOS immunoreactivity in the BNST in males and females. A, Mean + /- s.e.m. FOS+ cells in the BNST in the shock (SH) no shock (No-SH) in males and females. Asterisk indicates a significant difference in FOS between males receiving shocks and males receiving no shocks, ${ }^{*} p<0.01$. B , Correlation between the number of FOS + cells in the BNST and freezing behavior in males and females. Photomicrographs of the anterolateral BNST in males (C) and females $(\boldsymbol{D})$ in the shock and no shock conditions. Anterior-posterior distance from bregma (in $\mathrm{mm}$ ) is denoted in the lower right of each image.

training on day 2 , animals were placed in the conditioning chamber for 10 min and received three unsignaled footshocks (males $n=7$; females $n=8$ ) or no footshocks (males $n=6$, females $n=8$ ). Twenty-four hours later, animals were returned to the conditioning chambers for $10 \mathrm{~min}$. One hour after the completion of testing, animals were perfused.

To confirm that there were no a priori differences between groups, we analyzed freezing in the $30 \mathrm{~s}$ before the first shock on training day using a two-way ANOVA. We found no differences in freezing behavior, with no main effect of behavioral group, sex or sex $\times$ group interaction (ps > 0.05). To assess acquisition of context fear conditioning, we analyzed freezing during the $30 \mathrm{~s}$ after each shock (postshock freezing) and during the corresponding time points in the no shock groups. A two-way repeated measures ANOVA revealed a significant interaction between time and behavior $\left(F_{(2,50)}=8.71 ; p<0.001\right)$ with shock animals freezing more than no shock animals over time. There was no significant interaction between time and sex or time $\times \operatorname{sex} \times$ behavioral group interaction ( $p s>0.05$ ).

To assess context fear expression, we analyzed freezing during the $10 \mathrm{~min}$ test in males and females receiving shocks or no shocks using a two-way repeated measures ANOVA. We found a significant effect of behavior, with animals receiving shocks freezing more than no shock animals $\left(F_{(1,25)}=36.1\right.$; $p<0.0005)$, but no significant effect of time $\left(F_{(3.89}\right.$, 97.21) $=1.947 ; p=0.11$ with a Greenhouse-Geisser correction). The interaction between behavioral group and sex showed a trend toward significance $F_{(1,25)}=$ 3.88; $p=0.06$; Fig. 1B).

The number of FOS-positive cells was quantified across the two behavioral groups in the BNST, CE, LA, and BA. As there have been reports of lateralized activity in both the BNST (Luyck et al., 2020) and amygdala (Baker and Kim, 2004) following fear conditioning, we used mixed model ANOVAs to analyze FOS activity. A nested design accounted for laterality (left vs right hemisphere) within subjects and multiple measures (sex and behavioral group) between subjects. For the BNST, a mixed model ANOVA revealed a significant interaction between sex and behavioral group $\left(F_{(1,23)}=7.44 ; p=0.01\right.$; Fig. $\left.2 A\right)$, but no effect of laterality $\left(F_{(1,23)}=0.177 ; p=0.68\right)$. We then analyzed males and females separately. For males, a oneway ANOVA revealed a main effect of behavior $\left(F_{(1,9)}=\right.$ $13.03, p<0.01$ ) with more FOS-positive cells in the shock group than the no shock group (Fig. $2 A, C$ ). In contrast, there were no significant differences in the number of FOS positive cells in the BNST between the two female behavioral groups $\left(F_{(1,14)}=0.85 ; p=0.37\right.$; Fig. $\left.2 A, D\right)$. These data confirm that male but not female rats have higher levels of neuronal activity in the BNST during expression of contextual fear. We then examined whether freezing behavior correlated with FOS activity in the BNST. Because we found differences in FOS expression between sexes, we analyzed males and females separately. FOS expression was indeed correlated with freezing behavior in both males $(\rho=0.52, p<0.05)$ and females $(\rho=0.41, p<0.05$; Fig. $2 B)$. 

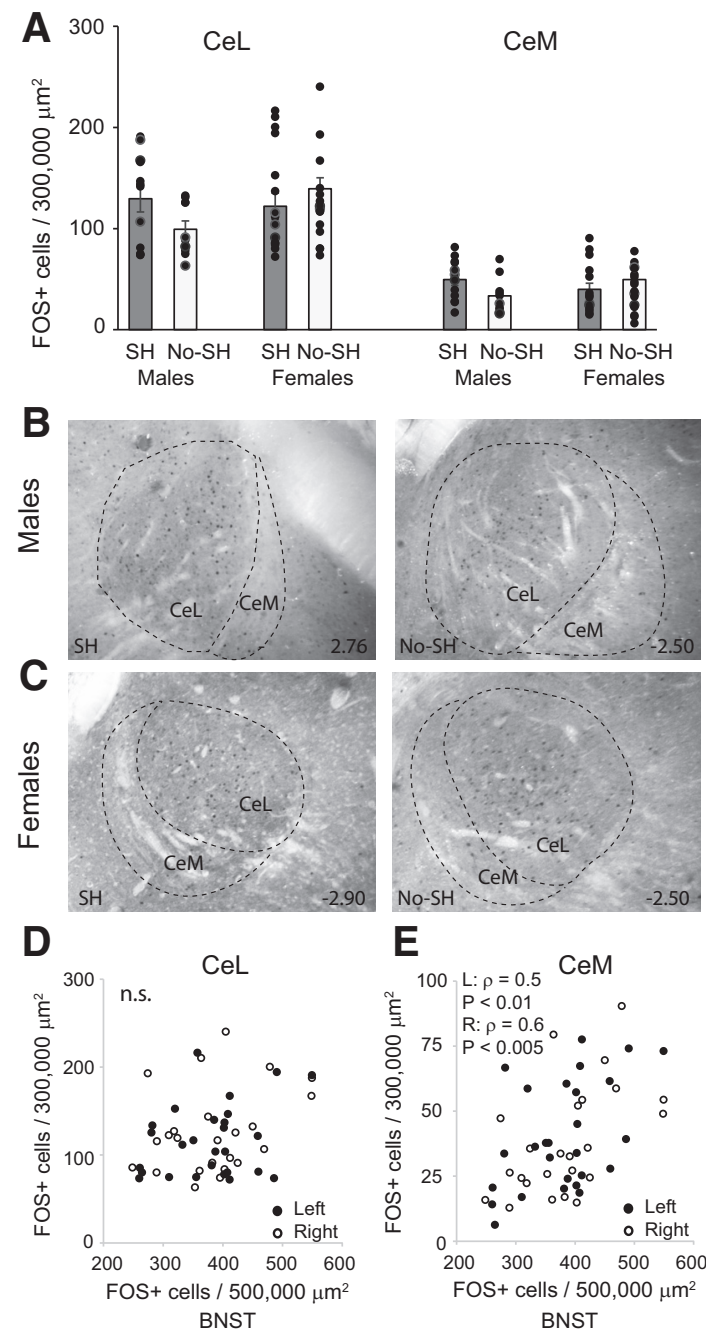

E

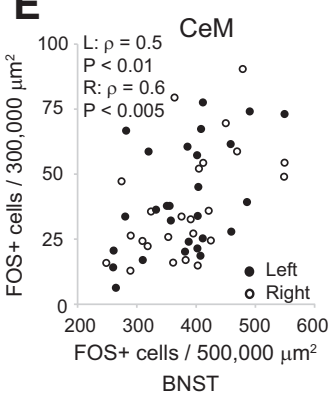

Figure 3. Context fear expression does not upregulate FOS in the CeL or CeM in males and females. $\boldsymbol{A}$, Mean +/- s.e.m. FOS+ cells in the CeL and CeM in the shock (SH) and no shock (No-SH) in males and females. Photomicrographs of the CE in males $(\boldsymbol{B})$ and females $(\boldsymbol{C})$ in the shock and no shock conditions, subdivided into $\mathrm{CeL}$ and $\mathrm{CeM}$. Anterior-posterior distance from bregma (in $\mathrm{mm}$ ) is denoted in the lower right of each image. $\boldsymbol{D}$, Correlation between the number of FOS + cells in the CeL and BNST in all animals. $\boldsymbol{E}$, Correlation between the number of FOS + cells in the CeM and BNST in all animals.

We analyzed FOS expression in the CeL and CeM separately. In the CeL, a mixed model ANOVA revealed no significant effect of behavioral group $\left(F_{(1,22)}=0.81 ; p=0.38\right)$, $\operatorname{sex}\left(F_{(1,22)}=0.57 ; p=0.46\right)$ or interaction $\left(F_{(1,22)}=0.74\right.$; $p=0.4$; Fig. $3 A-C)$. While there was a significant effect of laterality $\left(F_{(1,22)}=4.96 ; p<0.05\right)$, with greater FOS activation in the right $\mathrm{CeL}$, there was no interaction between laterality and either behavior or sex ( $p s>0.05$ ). Further, there was so significant correlation between FOS expression and freezing (left hemisphere $\rho=0.06 ; p=0.76$; right hemisphere: $\rho=0.02 ; p=0.94)$. In the CeM, a mixedmodel ANOVA revealed no significant effect of behavioral group $\left(F_{(1,23)}=0.85 ; p=0.37\right)$, $\operatorname{sex}\left(F_{(1,23)}=0.04 ; p=0.84\right)$, or interaction $F_{(1,23)}=1.23 ; p=0.28$, and no effect of laterality $F_{(1,23)}=0.55 ; p=0.47$; Fig. $\left.3 A-C\right)$. Further, there was so significant correlation between FOS expression and freezing (left hemisphere $\rho=0.08 ; p=0.69$; right hemisphere: $\rho=0.22 ; p=0.29$ ).

As the CeM receives direct input from the anterolateral BNST (Dong and Swanson, 2004), we correlated FOS expression between these two areas, analyzing left and right hemispheres separately. Indeed, FOS expression was correlated between the CeM and BNST (left hemisphere: $\rho=0.5$; $p<0.01$; right hemisphere: $\rho=0.6 ; p<0.005$ ), but not between the CeL and BNST (left hemisphere: $\rho=0.21 ; p=0.3$; right hemisphere: $\rho=0.28 ; p=0.18$; Fig. $3 D, E$ ).

In the LA, a mixed-model ANOVA revealed a significant effect of behavior $\left(F_{(1,18)}=4.66 ; p<0.05\right)$ with greater FOS activity in the shock animals. There was no main effect of $\operatorname{sex}\left(F_{(1,18)}=0.28, p=0.60\right)$ or interaction $\left(F_{(1,18)}=\right.$ $0.46, p=0.51)$, and no effect of laterality $\left(F_{(1,18)}=0.84\right.$, $p=0.37$; Fig. $4 A, E, F)$. FOS expression was correlated with freezing behavior for males $(\rho=0.56 ; p<0.05)$ but not females $(\rho=0.21 ; p=0.29$; Fig. $4 B)$. Within the BA, we found no significant effect of behavioral group $\left(F_{(1,17)}=\right.$ 1.77, $p=0.2)$, sex $\left(F_{(1,17)}=0.58, p=0.4\right)$ or interaction $\left(F_{(1,17)}=0.03, p=0.86\right)$, and no effect of laterality $\left(F_{(1,17)}=\right.$ $0.08, p=0.78$; Fig. $4 C)$. Correlating FOS expression with freezing behavior revealed a trend toward significance for males $(\rho=0.46 ; p=0.06)$ but not females $(\rho=-0.08$; $p=0.7$; Fig. 4D). In sum, context expression upregulated FOS expression in the LA and we found no differences in FOS expression between males and females in any of the three amygdalar regions.

\section{Paired and unpaired cued fear conditioning}

The BNST contributes to fear expression when cues are nonpredictive (Goode et al., 2019) while the LA is important for responses to cued fears (Repa et al., 2001). We trained animals with two different fear paradigms in which the cues either predicted a footshock (paired) or not (unpaired). During training, one group of animals was placed in the conditioning chamber $\mathrm{A}$ for $10 \mathrm{~min}$ and received three signaled footshocks with a 30-s tone co-terminating with the shock (males $n=6$; females $n=10$ ). In this behavioral design, the tone is paired with the shock and is thus a strong predictor of the shock. A second group of animals received the tones but no footshock (males $n=7$; females $n=8$; no shock). A third group of animals received three footshocks that were not paired with the tone (males $n=10$; females $n=10$; unpaired). The tone CS was thus unpaired with the shock and a poor predictor of the shock (Fig. 5A). Both males and females acquired freezing after being shocked (postshock freezing), in comparison to animals who just heard the tone (main effect of behavior $F_{(2,49)}=21.45 ; p<0.0001$; Fig. 5). There was no main effect of $\operatorname{sex}\left(F_{(1,45)}=0.53 ; p=0.5\right)$ or interaction between sex and behavioral group $\left(F_{(2,45)}=0.016 ; p=0.98\right)$.

Twenty-four hours later, animals were placed in a different conditioning chamber and received five CS tones. One hour after the completion of testing, animals were perfused. We first analyzed pre-CS freezing during the $30 \mathrm{~s}$ before the first tone. A two-way ANOVA (sex $\times$ behavioral group) revealed no effect of 
A

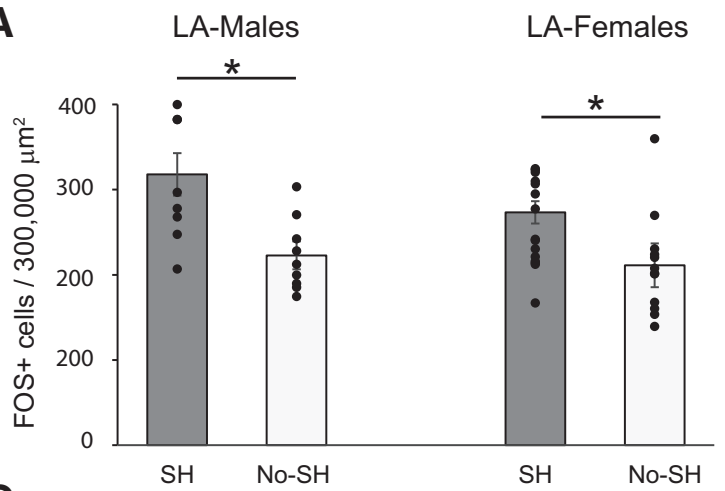

C

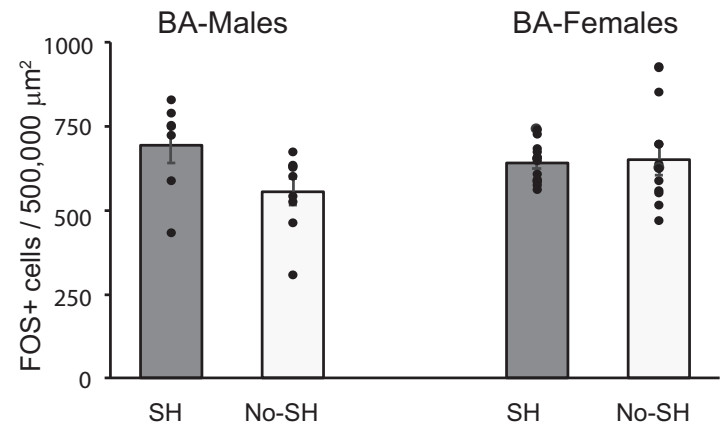

B

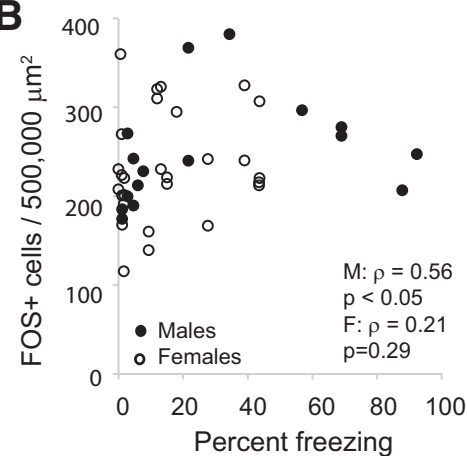

D

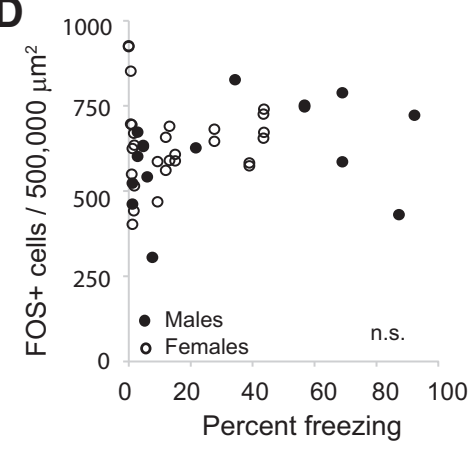

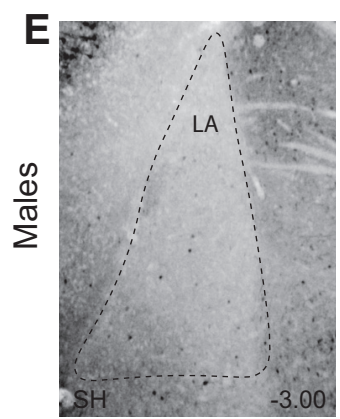
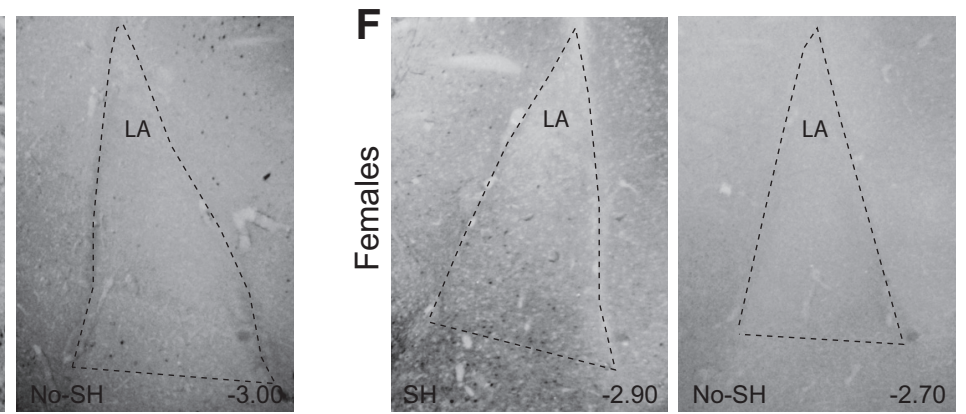

Figure 4. Context fear expression upregulates FOS in the LA but not BA in males and females. $\boldsymbol{A}$, Mean +/- s.e.m. FOS+ cells in the LA in the shock (SH) and no shock (No-SH) in males and females. Asterisk indicates a significant difference in FOS between shock animals and no-shock animals, ${ }^{*} p=0.01$. B , Correlation between the number of FOS + cells in the LA and freezing behavior in males and females. $\boldsymbol{C}$, Mean +/- s.e.m. FOS+ cells in the BA in the shock (SH) and no shock (No-SH) groups in males and females. $\boldsymbol{D}$, Correlation between the number of FOS + cells in the BA and freezing behavior in males and females. Photomicrographs of the LA in males $(\boldsymbol{E})$ and females $(\boldsymbol{F})$ in the shock and no shock conditions. Anterior-posterior distance from bregma (in $\mathrm{mm}$ ) is denoted in the lower right of each image.

behavioral group $\left(F_{(1,45)}=1.48 ; p=0.24\right) \operatorname{sex}\left(F_{(1,45)}=\right.$ 3.323; $p=0.08)$ or interaction $\left(F_{(2,45)}=1.27 ; p=0.29\right)$. As animals were trained in context $A$, and tested in context $\mathrm{B}$, it is possible some context generalization occurred. We thus performed a one-sample $t$ test on pre-CS freezing levels to determine whether freezing was significantly different from zero. Pre-CS freezing was not significantly different from zero for the animals receiving paired training (males: $p=0.36$; females: $p=0.31$ ) or unpaired training (males: $p=0.17$; females $p=0.07$ ). Finally, for animals receiving unpaired training, we tested whether freezing to the first tone was significantly different from pre-CS freezing. Unpaired $t$ tests revealed that both males $(p=0.03)$ and females $(p=0.009)$ exhibited significantly more freezing to the tone than the pre-CS period (Fig. 5B). Together, these data suggest that there was no significant context generalization between training and testing contexts.

We next analyzed freezing behavior to the five tone presentations. A two-way repeated measures ANOVA revealed a significant interaction between tone and behavioral group $\left(F_{(8,180)}=4.5 ; p<0.0001\right)$. We then performed two-way ANOVAs for each of the five tones with Tukey's HSD post hoc tests to determine significant differences between behavioral groups. During the first three tones, there were significant differences between all three behavioral groups (paired, unpaired and noshock; $p s<0.005)$. By tones 4 and 5 , there were differences between the paired groups and the other two behavioral groups ( $p s<0.0001$ ) but no difference between animals using unpaired tones and the no shock groups $(p=0.71, p=0.63)$. We also found a significant 
A
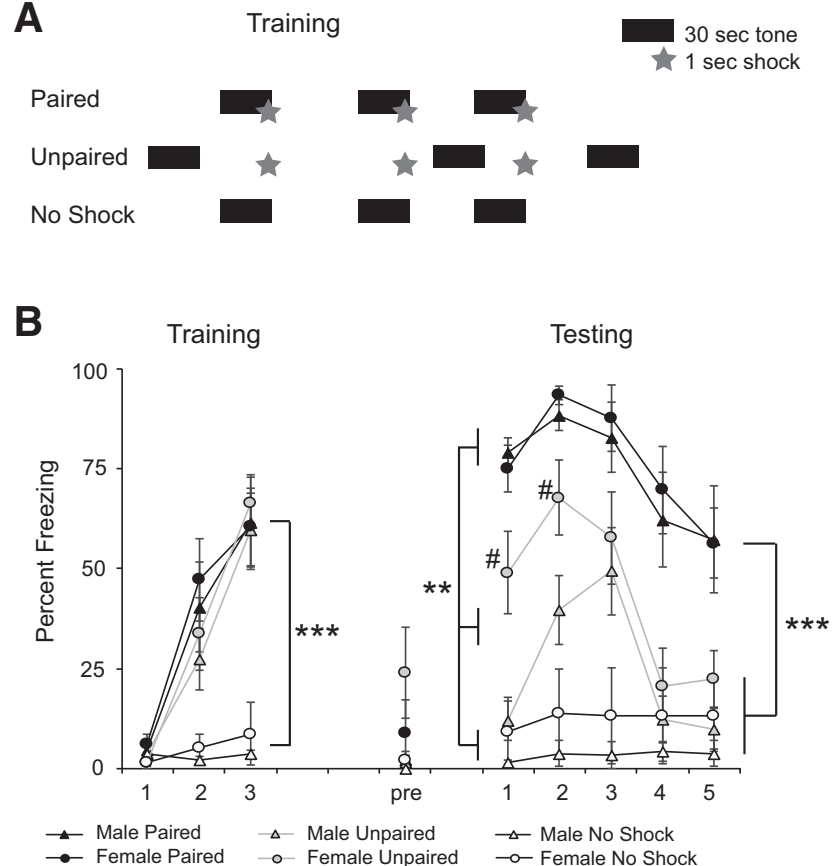

Figure 5. Conditioning in males and females to paired and unpaired cues. $\boldsymbol{A}$, Schematic of the training protocol in three behavioral groups: paired (P), unpaired (UP), and no shock. Bars represent 30-s CS tones. Stars represent 1-s footshocks. Animals in the cued group received three CS tones cotermininating with footshocks. Animals in the unpaired group received tones and shocks which were explicitly unpaired. Animals in the no-shock group received tones but no shocks. $\boldsymbol{B}$, Percent freezing +/- s.e.m. during each of the three tones during training, to the novel context before tone delivery during testing (pre) and during the five tone presentations during testing. Asterisks indicate differences in freezing between all three behavioral groups during the first three tones, and between cued animals and the other four groups during the last two tones; \# indicates a difference in freezing between males and females in the unpaired group during the first two tones; ${ }^{* *} p<0.005$, ${ }^{\star \star *} p<0.0001$, $\# p<0.05$.

effect of sex on freezing behavior for tones $1(p=$ $0.027)$ and $2(p=0.031$, Tukey's HSD), with females in the unpaired group freezing more than males trained in the unpaired group $(p=0.004, p=0.04$, Student's $t$ test; Fig. 5B). In sum, animals receiving paired training froze most, while animals trained using unpaired toneshocks showed an intermediate amount of fear expression during early testing, but extinguished quickly. In addition, female rats showed greater fear expression in the unpaired group than males.

We then analyzed the level of FOS activity in the BNST, $C E$, $L A$, and $B A$ in the three groups of animals. A mixedmodel ANOVA of FOS-positive cells in the BNST revealed a main effect of behavior $\left(F_{(2,43)}=21.37 ; p<0.001\right)$, but no effect of sex $\left(F_{(1,43)}=0.85 ; p=0.36\right)$ or interaction $\left(F_{(2,43)}=2.11 ; p=0.13\right)$ and no effect of laterality $\left(F_{(1,43)}=\right.$ $0.07 ; p=0.79$; Fig. $6 A, C, D)$. Tukey's HSD post hoc test revealed a significant difference in FOS expression between animals trained with unpaired tones and the other two behavioral groups ( $p s<0.001$ ), but no upregulation of FOS in the BNST in the paired group compared with the noshock group $(p=0.71)$. There was no correlation between FOS expression and freezing behavior (males: $\rho=0.04$; $p=0.82$; females: $\rho=0.17 ; p=0.23$; Fig. $6 B$ ). These data suggest that in males and females the BNST is involved in responding to cues which were unpaired with shocks during training and were thus nonpredictive.

We next analyzed FOS upregulation in the amygdala. Within the CeL, we found no significant effect of behavior $(p=0.93)$, sex $(p=0.11)$, interaction between sex $\times$ behavior $(p=0.83)$, and no effect of laterality $(p=0.89$; Fig. $6 E$ ). There was no correlation between FOS activity in the $\mathrm{CeL}$ and freezing behavior (left hemisphere: $p=0.51$; right hemisphere $p=0.88$ ). While there was no significant correlation between activity in the left CeL and left BNST $(p=0.14)$ there was a significant correlation in the right hemisphere ( $\rho=0.38 ; p=0.02)$. Within the $\mathrm{CeM}$, we found no significant effect of behavior $(p=0.31)$, sex $(p=0.16)$, interaction between sex $\times$ behavior $(p=0.76)$, and no effect of laterality $(p=0.92$; Fig. $6 E)$. There was no correlation between FOS activity in the $\mathrm{CeM}$ and freezing behavior (left hemisphere: $p=0.63$; right hemisphere $p=$ 0.77 ), or between FOS activity in the CeM and the BNST (left hemisphere: $p=0.1$; right hemisphere $p=0.68$ ).

Within the LA, we found a main effect of sex with more FOS-positive cells overall in females than in males $\left(F_{(1,29)}\right.$ $=31.56 ; p<0.001)$, and a sex $\times$ behavior interaction $\left(F_{(2,29)}=4.81 ; p<0.05\right)$, but no effect of laterality $\left(F_{(1,29)}=\right.$ $0.54 ; p=0.47$; Fig. $7 A, C, D)$. We then analyzed males and females separately. In females, one-way ANOVA revealed a significant effect of behavioral group $\left(F_{(2,16)}=4.03\right.$; $p=0.03$ ). Tukey's post hoc tests revealed a difference in FOS expression between the paired and unpaired groups $(p=0.03)$, but not between other groups. In males, a oneway ANOVA revealed no significant effect of behavioral group $\left(F_{(2,13)}=1.21 ; p=0.33\right)$. Because we found that behavior affected FOS expression in females, we analyzed whether FOS activity correlated with freezing in females. There was a trend toward a significant correlation within the left hemisphere ( $\rho=0.44 ; p=0.053$ ) but not the right $(\rho=0.08 ; p=0.75)$. In males, there was no correlation between FOS expression and freezing behavior: left hemisphere: $\rho=-0.12 ; p=0.63$ and right hemisphere: $\rho=$ $0.16 ; p=0.53$.

In the BA, a mixed-model ANOVA revealed a main effect of behavioral group $\left(F_{(2,30)}=8.41 ; p<0.001\right)$, but no effect of sex $\left(F_{(1,30)}=0.25 ; p=0.62\right)$ or interaction $\left(F_{(2,30)}=0.77 ; p=0.47\right)$ and no effect of laterality $\left(F_{(1,30)}=0.23 ; p=0.63\right)$ Tukey's HSD post hoc tests revealed higher numbers of FOS-positive cells in the unpaired group than in the other two groups ( $p s<0.005$; Fig. $7 B-D$ ). There was no significant correlation between FOS activity in the BA and freezing behavior (left hemisphere: $\rho=0.13 ; p=0.44$; right hemisphere: $\rho=$ $-0.05 ; p=0.8)$. In sum, for females, we observed opposite responses in the BLA, with the BA being more active during fear expression to unpaired cues, and the LA being more active during paired cued fear expression. In males, the BA was most active during fear expression to unpaired cues. 

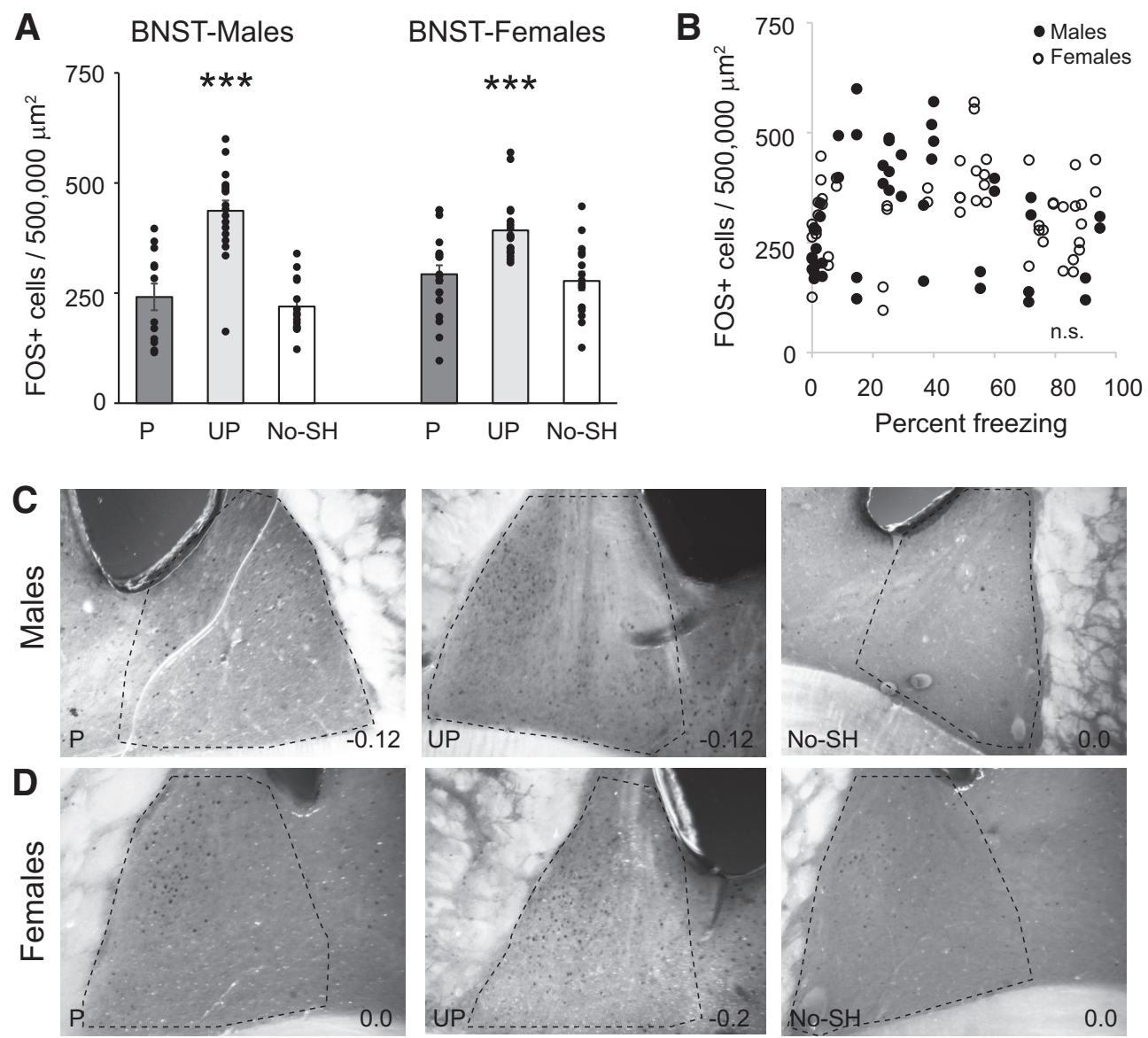

$\mathbf{E}$

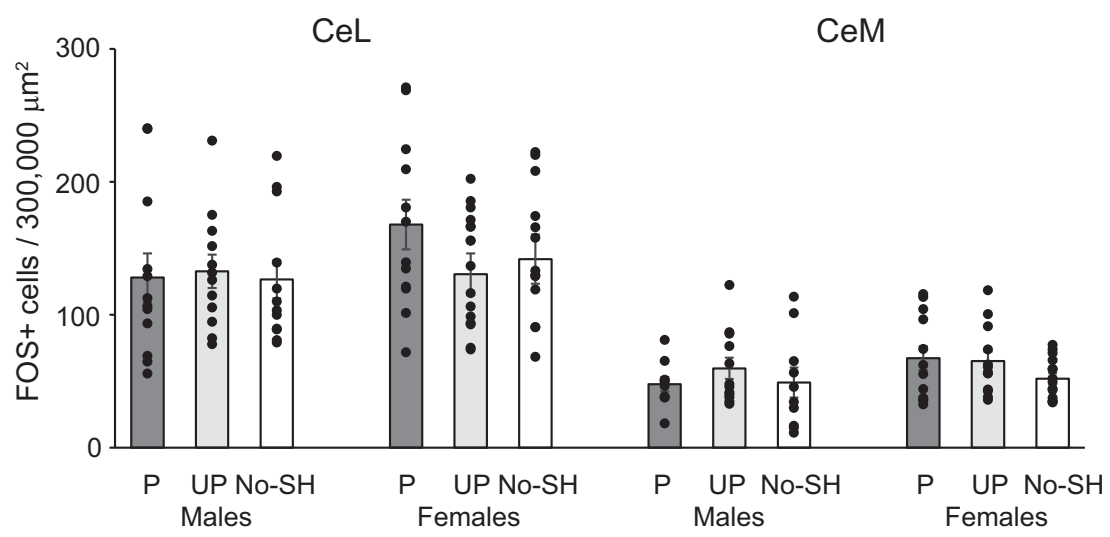

Figure 6. Conditioning to unpaired cues upregulates FOS in the BNST but not the CE in males and females. $\boldsymbol{A}$, Mean $+/-$ s.e.m. FOS + cells in the BNST in the paired (P), unpaired (UP), and no shock (No-SH) group in males and females. Asterisk indicates a significant difference in FOS between animals in the unpaired group and the other two behavioral groups, ${ }^{* \star *} p<0.001$. $\boldsymbol{B}$, Correlation between the number of FOS + cells in the BNST and freezing behavior in all males and females. Photomicrographs of the BNST in males $(\boldsymbol{C})$ and females $(\boldsymbol{D})$ in the P, UP, and No-SH groups. Anterior-posterior distance from bregma (in $\mathrm{mm}$ ) is denoted in the lower right of each image. $\boldsymbol{E}$, Mean +/- s.e.m. FOS+ cells in the CeL and CeM in the paired (P), unpaired (UP), and no shock (No-SH) group in males and females.

\section{Discussion}

In this study, we used context and cued fear conditioning paradigms combined with immunohistochemistry to compare neuronal activity in the BNST and amygdala of males and females rats and examine possible sex differences. In males, we found that the BNST and LA were active during context fear expression. In females, only the LA was active during context fear expression. In response to tones which were unpaired with shocks during training, females exhibited a greater freezing response 

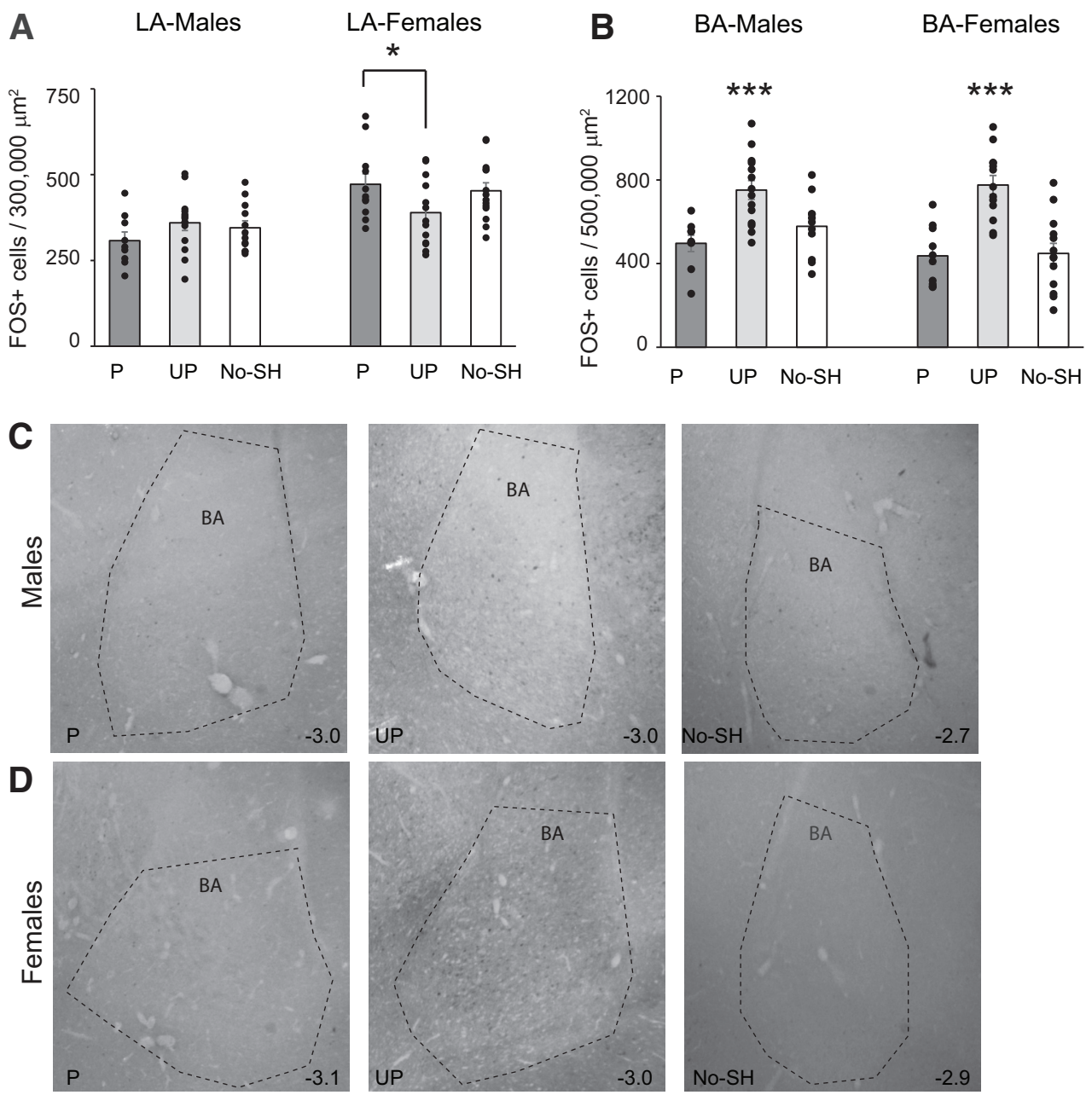

Figure 7. Conditioning to paired and unpaired cues upregulates FOS in the BLA. $\boldsymbol{A}$, Mean +/- s.e.m. FOS+ cells in the LA in the paired $(\mathrm{P})$, unpaired (UP), and no shock (No-SH) group in males and females. Asterisk indicates a significant difference in FOS between females in the paired group and the unpaired group. B, Mean +/- s.e.m. FOS+ cells in the BA in the paired (P), unpaired (UP), and no shock (No-SH) group in males and females. Asterisk indicates significant higher numbers of FOS-positive cells in the unpaired group than in the two other groups in males and females (ps $<0.005)$. $\boldsymbol{C}, \boldsymbol{D}$, Photomicrographs of the BA in males $(\boldsymbol{C})$ and females $(\boldsymbol{D})$ in the cued, random and no shock groups. Anterior-posterior distance from bregma (in mm) is denoted in the lower right of each image.

than males, but both sexes showed increased activity in the BNST and BA.

While sex differences in context fear conditioning have been previously reported, some have found stronger conditioning in males (Maren et al., 1994; Anagnostaras et al., 1998; Colon et al., 2018), stronger conditioning in females (Moore et al., 2010; Keiser et al., 2017), or no differences (Kosten et al., 2006; Dachtler et al., 2011; Urien et al., 2021). Here, context fear expression upregulated FOS activity in the BNST in males, but not in females exposed to the same training paradigm. However, it is possible that a region of the BNST outside of the anterodorsal area analyzed in this study contributes to context fear expression in females. These data confirm the involvement of the BNST in context fear conditioning in males (Sullivan et al., 2004; Duvarci et al., 2009; Urien et al., 2021).

Context fear expression also resulted in upregulation of FOS in the LA in both sexes. Upregulation of ARC, FOS, and EGR1 in the LA in response to context fear conditioning has been reported (Malkani and Rosen, 2000; Wilson and Murphy, 2009; Chaaya et al., 2019) and the LA also exhibits context-dependent neuronal activity (Hobin et al., 2003). However, these previous studies were performed only in males. Our data suggests that the LA is similarly involved in context fear expression in females. Context fear conditioning requires animals to learn a conjunctive representation of context from multimodal sensory cues (Rudy and O'Reilly, 1999). One hypothesis for sex differences in context fear conditioning is that females are less efficient in forming context representations or use different strategies than males (Wiltgen et al., 2001; Monfort et al., 2015; Yagi et al., 2016). Our finding that FOS activation in the LA was increased in females during context fear expression supports this hypothesis, as FOS expression also increased in the LA following cued fear expression in females.

We performed correlation analyses for individual animals to assess whether freezing behavior was correlated 
with FOS activity in the BNST and amygdalar regions. Expression of context fear conditioning was indeed correlated with FOS activity in the BNST and LA, but not the CE or the BA. This analysis further suggests the involvement of the BNST and LA in context fear expression.

During our paired conditioning paradigm, males and females exhibited the same levels of freezing in response to a discrete cue. Indeed, there are few reports of sex differences in cued fear conditioning (Baker-Andresen et al., 2013; Fenton et al., 2014; Voulo and Parsons, 2017; Day and Stevenson, 2020), although some have reported reduced (Pryce et al., 1999; Baran et al., 2010) or enhanced (Gresack et al., 2009) freezing in females. Additionally, freezing to paired cues was higher than to unpaired cues in both sexes in agreement with previous studies (Goode et al., 2019; Glover et al., 2020) Interestingly, females responded more than males to the unpaired cues during fear expression. Knowing that females exhibit more generalization of fear (Day et al., 2016; Keiser et al., 2017; Krueger and Sangha, 2021), it is possible that the unpaired cues used in this conditioning paradigm created fear generalization in females.

However, there was no fear generalization to the testing context in animals trained with paired or unpaired cues. Specifically, there was no significant amount of freezing during the pre-CS period for any behavioral group. Thus, freezing to the tones during testing did not represent reactivation of a generalized context.

The earliest models of Pavlovian fear conditioning stated that learning depends on contingency, or the ability of the CS to predict US occurrence (Rescorla, 1968). Here, in the unpaired condition, we delivered CS cues which were explicitly unpaired with the US. Others have used the same behavioral paradigm of negatively correlating a CS and US which can result in the CS signifying a period of safety (Nahmoud et al., 2021). This is accompanied by depression of CS-induced activity in the LA (Rogan et al., 2005). Any weak learning of the association between the unpaired CS and US involves activation of the BNST (Goode et al., 2020). To our knowledge, the BNST's involvement in fear expression to unpaired, nonpredictive cues has been assessed only in males. Here, we found upregulation of FOS in the BNST in both males and females.

FOS was also upregulated in the BA in response to unpaired cues in both males and females. Interestingly, the protein kinase ERK $1 / 2$ is also active in the BA after an unpaired conditioning protocol (Trifilieff et al., 2007). Individual neurons within the BA respond to safety cues presented alone, as well as safety and fear cues presented together (Sangha et al., 2013; Kyriazi et al., 2018, 2020). In contrast, neural activity in the LA seems to be downregulated in response to safety cues (Rogan et al., 2005). Moreover, the postsynaptic density on dendrites in the LA decreases after conditioning with unpaired CSs (Ostroff et al., 2010). Accordingly, we did not observe changes in FOS expression in the LA in the unpaired cue groups.

We performed correlation analyses in individual animals to assess whether freezing behavior in the paired, unpaired and no shock groups was correlated with FOS activity in the BNST and amygdalar regions. While there were no significant correlations in any regions, this is not surprising as freezing was highest in the paired groups, but FOS activity was highest in the unpaired groups in the BNST and BA.

Across our experiments, we did not observe any changes in FOS expression in the CE. Neuronal activity by somatostatin-containing neurons in the CeL contributes to fear acquisition, whereas conditioned fear responses are driven by output neurons in the CeM (Ciocchi et al., 2010; Sun et al., 2020). Interestingly, in animals undergoing context fear conditioning, we found that FOS expression was correlated in the BNST and CeM. Indeed, the anterolateral BNST projects more strongly to the CeM than the CeL (Dong and Swanson, 2004). Our data suggests that this BNST-CeM pathway is active during the expression of context fear conditioning. Future studies should analyze the contributions of different CE neuronal subtypes to fear conditioning, and compare males and females. Interestingly, BNST and CeM activity was not correlated in animals undergoing paired or unpaired conditioning, and BNST activity was not correlated with freezing behavior in these animals. Thus, while the BNST is recruited by both context fear expression and fear expression to unpaired stimuli, these contrasting results suggest possible circuit-level differences in BNST involvement in these two types of learning.

Surprisingly, expression of paired cued fear conditioning upregulated FOS in the LA in females but not in males. Many previous studies have demonstrated that the LA is required for the acquisition of cued fear conditioning and that acquisition upregulates the expression of immediateearly genes in the LA (Collins and Paré, 2000; Repa et al., 2001; Ploski et al., 2008). However, there are few studies measuring FOS in the LA following the expression of cued fear conditioning. Some find no increase in FOS in the LA (Hall et al., 2001), others find an increase in the most dorsal portion of the LA, but not in the ventral LA (Knapska and Maren, 2009); however, these experiments were performed only in males. There is evidence that despite similar behavioral responses to cued fear conditioning, males and females might possess fundamental sex differences in fear circuitry structure (Gruene et al., 2015). Thus, the possible differential contribution of the LA to fear expression in males and females should be explored further.

Overall, our findings suggest that in males, the BNST is important for processing fear responses to context and to unpredictable threats. In females, the LA is active during context fear expression. While both the BNST and the BA showed upregulation of FOS in response to cues unpaired to aversive shocks, females exhibited a stronger fear response to these cues. The aim of these experiments was to not only document differences in the magnitude of freezing behavior in males and females, but to consider the neural networks engaged by fear expression. Understanding which circuits are recruited during memory processes in both males and females will also help identify the mechanisms underlying the differential vulnerability of men and women to anxiety disorders and PTSD (McLean et al., 2011; Tronson and Keiser, 2019). 


\section{References}

Alheid GF, Heimer L (1988) New perspectives in basal forebrain organization of special relevance for neuropsychiatric disorders: the striatopallidal, amygdaloid, and corticopetal components of substantia innominata. Neuroscience 27:1-39.

Allen LS, Gorski RA (1990) Sex difference in the bed nucleus of the stria terminalis of the human brain. J Comp Neurol 302:697-706.

Altemus M, Sarvaiya N, Epperson CN (2014) Sex differences in anxiety and depression clinical perspectives. Front Neuroendocrinol 35:320-330.

Anagnostaras SG, Maren S, Decola JP, Lane NI, Gale GD, Schlinger BA, Fanselow MS (1998) Testicular hormones do not regulate sexually dimorphic Pavlovian fear conditioning or perforant-path longterm potentiation in adult male rats. Behav Brain Res 92:1-9.

Archer J (1975) Rodent sex differences in emotional and related behavior. Behav Biol 14:451-479.

Avery SN, Clauss JA, Blackford JU (2016) The human BNST: functional role in anxiety and addiction. Neuropsychopharmacology 41:126-141.

Baker KB, Kim JJ (2004) Amygdalar lateralization in fear conditioning: evidence for greater involvement of the right amygdala. Behav Neurosci 118:15-23.

Baker-Andresen D, Flavel CR, Li X, Bredy TW (2013) Activation of BDNF signaling prevents the return of fear in female mice. Learn Mem 20:237-240.

Baran SE, Armstrong CE, Niren DC, Conrad CD (2010) Prefrontal cortex lesions and sex differences in fear extinction and perseveration. Learn Mem 17:267-278.

Brinkmann L, Buff C, Feldker K, Tupak SV, Becker MPI, Herrmann MJ, Straube T (2017a) Distinct phasic and sustained brain responses and connectivity of amygdala and bed nucleus of the stria terminalis during threat anticipation in panic disorder. Psychol Med 47:2675-2688.

Brinkmann L, Buff C, Neumeister P, Tupak SV, Becker MPI, Herrmann MJ, Straube T (2017b) Dissociation between amygdala and bed nucleus of the stria terminalis during threat anticipation in female post-traumatic stress disorder patients. Hum Brain Mapp 38:2190-2205.

Chaaya N, Jacques A, Belmer A, Richard DJ, Bartlett SE, Battle AR, Johnson LR (2019) Localization of contextual and context removed auditory fear memory within the basolateral amygdala complex. Neuroscience 398:231-251.

Ciocchi S, Herry C, Grenier F, Wolff SBE, Letzkus JJ, Vlachos I, Ehrlich I, Sprengel R, Deisseroth K, Stadler MB, Müller C, Lüthi A (2010) Encoding of conditioned fear in central amygdala inhibitory circuits. Nature 468:277-282.

Collins DR, Paré D (2000) Differential fear conditioning induces reciprocal changes in the sensory responses of lateral amygdala neurons to the CS(+) and CS(-). Learn Mem 7:97-103.

Colon LM, Poulos AM (2020) Contextual processing elicits sex differences in dorsal hippocampus activation following footshock and context fear retrieval. Behav Brain Res 393:112771.

Colon L, Odynocki N, Santarelli A, Poulos AM (2018) Sexual differentiation of contextual fear responses. Learn Mem 25:230-240.

Dachtler J, Fox KD, Good MA (2011) Gender specific requirement of GluR1 receptors in contextual conditioning but not spatial learning. Neurobiol Learn Mem 96:461-467.

Davis M, Walker DL, Miles L, Grillon C (2010) Phasic vs sustained fear in rats and humans: role of the extended amygdala in fear vs anxiety. Neuropsychopharmacology 35:105-135.

Day HLL, Stevenson CW (2020) The neurobiological basis of sex differences in learned fear and its inhibition. Eur J Neurosci 52:24662486.

Day HLL, Reed MM, Stevenson CW (2016) Sex differences in discriminating between cues predicting threat and safety. Neurobiol Learn Mem 133:196-203.

Day HLL, Suwansawang S, Halliday DM, Stevenson CW (2020) Sex differences in auditory fear discrimination are associated with altered medial prefrontal cortex function. Sci Rep 10:6300. del Abril A, Santiago S, Guillamón A (1987) The bed nucleus of the stria terminalis in the rat: regional sex differences controlled by gonadal steroids early after birth. Brain Res 429:295-300.

Dong HW, Swanson LW (2004) Organization of axonal projections from the anterolateral area of the bed nuclei of the stria terminalis. J Comp Neurol 468:277-298.

Duvarci S, Bauer EP, Paré D (2009) The bed nucleus of the stria terminalis mediates inter-individual variations in anxiety and fear. $J$ Neurosci 29:10357-10361.

Fanselow MS, LeDoux JE (1999) Why we think plasticity underlying Pavlovian fear conditioning occurs in the basolateral amygdala. Neuron 23:229-232.

Fanselow MS, Dong HW (2010) Are the dorsal and ventral hippocampus functionally distinct structures? Neuron 65:7-19.

Fenton GE, Pollard AK, Halliday DM, Mason R, Bredy TW, Stevenson CW (2014) Persistent prelimbic cortex activity contributes to enhanced learned fear expression in females. Learn Mem 21:55-60.

Figel B, Brinkmann L, Buff C, Heitmann CY, Hofmann D, Bruchmann M, Becker MPI, Herrmann MJ, Straube T (2019) Phasic amygdala and BNST activation during the anticipation of temporally unpredictable social observation in social anxiety disorder patients. Neuroimage Clin 22:101735.

Fox AS, Oler JA, Trom do PM, Fudge JL, Kalin NH (2015) Extending the amygdala in theories of threat processing. Trends Neurosci 38:319-329.

Gamwell K, Nylocks M, Cross D, Bradley B, Norrholm SD, Jovanovic T (2015) Fear conditioned responses and PTSD symptoms in children: sex differences in fear-related symptoms. Dev Psychobiol 57:799-808.

Glover LR, McFadden KM, Bjorni M, Smith SR, Rovero NG, OreiziEsfahani S, Yoshida T, Postle AF, Nonaka M, Halladay LR, Holmes A (2020) A prefrontal-bed nucleus of the stria terminalis circuit limits fear to uncertain threat. ELife 9:60812.

Goode TD, Ressler RL, Acca GM, Miles OW, Maren S (2019) Bed nucleus of the stria terminalis regulates fear to unpredictable threat signals. Elife 8:e46525.

Goode TD, Acca GM, Maren S (2020) Threat imminence dictates the role of the bed nucleus of the stria terminalis in contextual fear. Neurobiol Learn Mem 167:107116.

Gorman JM, Kent JM, Sullivan GM, Coplan JD (2000) Neuroanatomical hypothesis of panic disorder, revised. Am J Psychiatry 157: 493-505.

Gresack JE, Schafe GE, Orr PT, Frick KM (2009) Sex differences in contextual fear conditioning are associated with differential ventral hippocampal extracellular signal-regulated kinase activation. Neuroscience 159:451-467.

Gruene TM, Roberts E, Thomas V, Ronzio A, Shansky RM (2015) Sex-specific neuroanatomical correlates of fear expression in prefrontal-amygdala circuits. Biol Psychiatry 78:186-193.

Hall J, Thomas KL, Everitt BJ (2001) Fear memory retrieval induces CREB phosphorylation and FOS expression within the amygdala. Eur J Neurosci 13:1453-1458.

Haufler D, Nagy FZ, Paré D (2013) Neuronal correlates of fear conditioning in the bed nucleus of the stria terminalis. Learn Mem 20:633-641.

Herry C, Ciocchi S, Senn V, Demmou L, Müller C, Lüthi A (2008) Switching on and off fear by distinct neuronal circuits. Nature 454:600-606.

Hines M, Allen LS, Gorski RA (1992) Sex differences in subregions of the medial nucleus of the amygdala and the bed nucleus of the stria terminalis of the rat. Brain Res 579:321-326.

Hobin JA, Goosens KA, Maren S (2003) Context-dependent neuronal activity in the lateral amygdala represents fear memories after extinction. J Neurosci 23:8410-8416.

Keiser AA, Turnbull LM, Darian MA, Feldman DE, Song I, Tronson NC (2017) Sex differences in context fear generalization and recruitment of hippocampus and amygdala during retrieval. Neuropsychopharmacology 42:397-407. 
Kimerling R, Allen MC, Duncan LE (2018) Chromosomes to social contexts: sex and gender differences in PTSD. Curr Psychiatry Rep 20:114.

Knapska E, Maren S (2009) Reciprocal patterns of c-Fos expression in the medial prefrontal cortex and amygdala after extinction and renewal of conditioned fear. 16:486-493.

Kosten TA, Lee HJ, Kim JJ (2006) Early life stress impairs fear conditioning in adult male and female rats. Brain Res 1087:142-150.

Krettek JE, Price JL (1978) Amygdaloid projections to subcortical structures within the basal forebrain and brainstem in the rat and cat. J Comp Neurol 178:225-254.

Kyriazi P, Headley DB, Paré D (2018) Multi-dimensional coding by basolateral amygdala neurons. Neuron 99:1315-1328.

Kyriazi P, Headley DB, Paré D (2020) Different multidimensional representations across the amygdalo-prefrontal network during an approach-avoidance task. Neuron 107:717-730.

Krueger JN, Sangha S (2021) On the basis of sex: differences in safety discrimination vs. conditioned inhibition. Behav Brain Res 400:113024

Lonsdorf TB, Kalisch R (2011) A review on experimental and clinical genetic associations studies on fear conditioning, extinction and cognitive-behavioral treatment. Transl Psychiatry 1: e41.

Luyck K, Scheyltjens I, Nuttin B, Arckens L, Luyten L (2020) c-Fos expression following context conditioning and deep brain stimulation in the bed nucleus of the stria terminalis in rats. Sci Rep 10:20529.

Malkani S, Rosen JB (2000) Specific induction of early growth response gene 1 in the lateral nucleus of the amygdala following contextual fear conditioning in rats. Neuroscience 97:693-702.

Maren S, Holmes A (2016) Stress and fear extinction. Neuropsychopharmacology 41:58-79.

Maren S, De Oca B, Fanselow MS (1994) Sex differences in hippocampal long-term potentiation (LTP) and Pavlovian fear conditioning in rats: positive correlation between LTP and contextual learning. Brain Res 661:25-34.

McLean CP, Asnaani A, Litz BT, Hofmann SG (2011) Gender differences in anxiety disorders: prevalence, course of illness, comorbidity and burden of illness. J Psychiatr Res 45:10271035.

Milad MR, Rauch SL, Pitman RK, Quirk GJ (2006) Fear extinction in rats: implications for human brain imaging and anxiety disorders. Biol Psychol 73:61-71.

Monfort P, Gomez-Gimenez B, Llansola M, Felipo V (2015) Gender differences in spatial learning, synaptic activity, and long-term potentiation in the hippocampus in rats: molecular mechanisms. ACS Chem Neurosci 6:1420-1427.

Moore MD, Cushman J, Chandra D, Homanics GE, Olsen RW, Fanselow MS (2010) Trace and contextual fear conditioning is enhanced in mice lacking the alpha4 subunit of the GABA(A) receptor. Neurobiol Learn Mem 93:383-387.

Naaz F, Knight LK, Depue BE (2019) Explicit and ambiguous threat processing: functionally dissociable roles of the amygdala and bed nucleus of the stria terminalis. J Cogn Neurosci 31:543-559.

Nahmoud I, Ganay Vasquez J, Cho H, Dennis-Tiwary T, Likhtik E (2021) Salient safety conditioning improves novel discrimination learning. Behav Brain Res 397:112907.

Ostroff L, Cain CK, Bedont J, Monfils MH, LeDoux JE (2010) Fear and safety learning differentially affect synapse size and dendritic translation in the lateral amygdala. Proc Natl Acad Sci USA 107:9418-9423.

Pape HC, Pare D (2010) Plastic synaptic networks of the amygdala for the acquisition, expression, and extinction of conditioned fear. Physiol Rev 90:419-463.

Paré D, Smith Y, Paré JF (1995) Intra-amygdaloid projections of the basolateral and basomedial nuclei in the cat: Phaseolus vulgarisleucoagglutinin anterograde tracing at the light and electron microscopic level. Neuroscience 69:567-583.
Ploski JE, Pierre VJ, Smucny J, Park K, Monsey MS, Overeem KA, Schafe GE (2008) The activity-regulated cytoskeletal-associated protein (Arc/Arg3.1) is required for memory consolidation of Pavlovian fear conditioning in the lateral amygdala. J Neurosci 28:12383-12395.

Polston EK, Gu G, Simerly RB (2004) Neurons in the principal nucleus of the bed nuclei of the stria terminalis provide a sexually dimorphic GABAergic input to the anteroventral periventricular nucleus of the hypothalamus. Neuroscience 123:793803.

Pryce CR, Lehmann J, Feldon J (1999) Effect of sex on fear conditioning is similar for context and discrete CS in Wistar, Lewis and Fischer rat strains. Pharmacol Biochem Behav 64:753759.

Rabellino D, Densmore M, Harricharan S, Jean T, Mckinnon MC, Lanius RA (2018) Resting-state functional connectivity of the bed nucleus of the stria terminalis in post-traumatic stress disorder and its dissociative subtype. Hum Brain Mapp 39:13671379.

Repa JC, Muller J, Apergis J, Desrochers TM, Zhou Y, LeDoux JE (2001) Two different lateral amygdala cell populations contribute to the initiation and storage of memory. Nat Neurosci 4:724-731.

Rescorla RA (1968) Probability of shock in the presence and absence of CS in fear conditioning. J Comp Physiol Psychol 66:1-5.

Rogan MT, Leon KS, Perez DL, Kandel ER (2005) Distinct neural signatures for safety and danger in the amygdala and striatum of the mouse. Neuron 46:309-320.

Rudy JW, O'Reilly RC (1999) Contextual fear conditioning, conjunctive representations, pattern completion, and the hippocampus. Behav Neurosci 113:867-880.

Sangha S, Chadick JZ, Janak PH (2013) Safety encoding in the basal amygdala. J Neurosci 33:3744-3751.

Shackman AJ, Fox AS (2021) Two decades of anxiety neuroimaging research: new insights and a look to the future. Am J Psychiatry 178:106-109.

Shin JW, Geerling JC, Loewy AD (2008) Inputs to the ventrolateral bed nucleus of the stria terminalis. J Comp Neurol 511:628-657.

Smith Y, Paré D (1994) Intra-amygdaloid projections of the lateral nucleus of the cat: PHA-L anterograde labeling combined with postembedding GABA and glutamate immunocytochemistry. J Comp Neurol 342:232-248.

Sripada RK, King AP, Garfinkel SN, Wang X, Sripada CS, Welsh RC, Liberzon I (2012) Altered resting state amygdala functional connectivity in men with posttraumatic stress disorder. J Psychiatry Neurosci 37:241-249.

Stefanova N, Ovtscharoff W (2007) Sexual dimorphism of the bed nucleus of the stria terminalis and the amygdala. Adv Anat Embryol Cell Biol 185:1-73.

Sullivan GM, Apergis J, Bush DEA, Johnson LR, Hou M, LeDoux JE (2004) Lesions in the bed nucleus of the stria terminalis disrupt corticosterone and freezing responses elicited by a contextual but not by a specific cue-conditioned fear stimulus. Neuroscience 128:7-14.

Sun N, Cassell MD (1993) Intrinsic GABAergic neurons in the rat central extended amygdala. J Comp Neurol 330:381-404.

Sun Y, Qian L, Xu L, Hunt S, Sah P (2020) Somatostatin neurons in the central amygdala mediate anxiety by disinhibition of the central sublenticular extended amygdala. Mol Psychiatry.

Swanson LW, Petrovich GD (1998) What is the amygdala? Trends Neurosci 21:323-331.

Trifilieff P, Calandreau L, Herry C, Mons N, Micheau J (2007) Biphasic ERK1/2 activation in both the hippocampus and amygdala may reveal a system consolidation of contextual fear memory. Neurobiol Learn Mem 88:424-434.

Tronson NC, Keiser AA (2019) A dynamic memory systems framework for sex differences in fear memory. Trends Neurosci 42:680692. 
Urien L, Stein N, Ryckman A, Bell L, Bauer EP (2021) Extended amygdala circuits are differentially activated by context fear conditioning in male and female rats. Neurobiol Learn Mem 180:107401.

Voulo ME, Parsons RG (2017) Response-specific sex difference in the retention of fear extinction. Learn Mem 24:245-251.

Walker DL, Toufexis DJ, Davis M (2003) Role of the bed nucleus of the stria terminalis versus the amygdala in fear, stress, and anxiety. Eur J Pharmacol 463:199-216.
Wilson YM, Murphy M (2009) A discrete population of neurons in the lateral amygdala is specifically activated by contextual fear conditioning. Learn Mem 16:357-361.

Wiltgen BJ, Sanders MJ, Behne NS, Fanselow MS (2001) Sex differences, context preexposure, and the immediate shdck Deficit in Pavlovian context conditioning with mice. Behav Neurosci 115:26-32.

Yagi S, Chow C, Lieblich SE, Galea LAM (2016) Sex and strategy use matters for pattern separation, adult neurogenesis, and immediate early gene expression in the hippocampus. Hippocampus 26:87-101. 